\title{
Novalis Stereotactic Radiosurgery for Spinal Dural Arteriovenous Fistula
}

\author{
Kyoung-Su Sung, M.D., Young-Jin Song, M.D., Ki-Uk Kim, M.D. \\ Brain Tumor Institute, Novalis Stereotactic Radiosurgery Center, Department of Neurosurgery, College of Medicine, Dong-A University, Busan, Korea
}

The spinal dural arteriovenous fistula (SDAVF) is rare, presenting with progressive, insidious symptoms, and inducing spinal cord ischemia and myelopathy, resulting in severe neurological deficits. If physicians have accurate and enough information about vascular anatomy and hemodynamics, they achieve the good results though the surgery or endovascular embolization. However, when selective spinal angiography is unsuccessful due to neurological deficits, surgery and endovascular embolization might be failed because of inadequate information. We describe a patient with a history of vasospasm during spinal angiography, who was successfully treated by spinal stereotactic radiosurgery using Novalis system.

Key Words : Spinal vascular disease $\cdot$ Dural arteriovenous fistula $\cdot$ Stereotactic radiosurgery.

\section{INTRODUCTION}

The spinal dural arteriovenous fistula (SDAVF) is the most common type of spinal vascular malformation, but it is rare condition in overall incidence $e^{5,6,10,13,17,18,20)}$. It is characterized by progressive, insidious, and non-specific symptoms that are similar to those of more common etiology, such as degenerative spinal disorder and peripheral neuropathy ${ }^{5,13,19,20)}$. The fistulas of SDAVF are located intradurally at the sleeve of the nerve root, and the obliteration of fistulas is the treatment goal for SDAVF $\mathrm{SP}^{5,13,18,22,23)}$. SDAVF can be treated by surgical interruption and endovascular embolization. To help ensure successful treatment, selective spinal angiography is necessary to provide information about vascular architectures ${ }^{5,6,12,15,18,19,22)}$. However, spinal angiography has been shown to cause paraparesis in several cases ${ }^{6,8,15-17)}$.

We present a patient with SDAVF and a history of paraparesis during spinal angiography who was treated successfully using stereotactic radiosurgery (SRS) using Novalis system.

\section{CASE REPORT}

A 43-year-old man presented with slow progression of back pain, voiding difficulty, and boring pain on both lower extremities during 5 months. His symptoms worsened 5 days prior to his presentation to our hospital. Neurological examination showed motor weakness of grade IV in both legs and his anal tone was grade zero. Sensory changes, such as hypesthesia and analgesia were presented below the T9 level. About 14 years ago, he had pain in the left leg and was diagnosed with spinal arteriovenous malformation. At that time, magnetic resonance imaging (MRI) of the thoracolumbar spine revealed a vascular anomaly at the thoracolumbar level, and physicians performed spinal angiography for definite treatment. However, spinal angiography had failed three times in two other hospitals due to vasospasm and paraparesis. He recovered from these symptoms spontaneously, and he had not undergone any treatment thereafter.

MRI in our hospital showed a vascular anomaly with enhancement at the T12, L1, and L2 levels (Fig. 1A). Axial images of the L1 level revealed a mass lesion, located on the left side of the intraspinal canal (Fig. 1B). We recommended selective spinal angiography, but the patient refused because of his experience, requesting a non-invasive technique for diagnosis and treatment. We planned SRS using the Novalis system (BrainLAB ${ }^{\circledR}$, Heimstetten, Germany). However, we required an alternative modality to selective spinal angiography for obtaining accurate information on diagnosis, level of the lesion, and follow-up after treatment. Thus, a three-dimensional volumetric sagittal timeresolved imaging of contrast kinetics (TRICKS) abdominal magnetic resonance angiography (MRA) using 1.5T MRI system were performed in quiet respiration $\left(\mathrm{TR} / \mathrm{TE} / \mathrm{flip}=4.2 / 1.1 / 45^{\circ}\right.$, FOV

• Received : September 3, 2014 • Revised : May 15, 2015 •Accepted : May 30, 2015

- Address for reprints : Ki-Uk Kim, M.D.

Brain Tumor Institute, Novalis Stereotactic Radiosurgery Center, Department of Neurosurgery, College of Medicine, Dong-A University, 26 Daesingongwon-ro, Seo-gu, Busan 49201, Korea

Tel : +82-51-240-5241, Fax : +82-51-242-6714, E-mail : kukim@donga.ac.kr

- This is an Open Access article distributed under the terms of the Creative Commons Attribution Non-Commercial License (http://creativecommons.org/licenses/by-nc/3.0) which permits unrestricted non-commercial use, distribution, and reproduction in any medium, provided the original work is properly cited. 

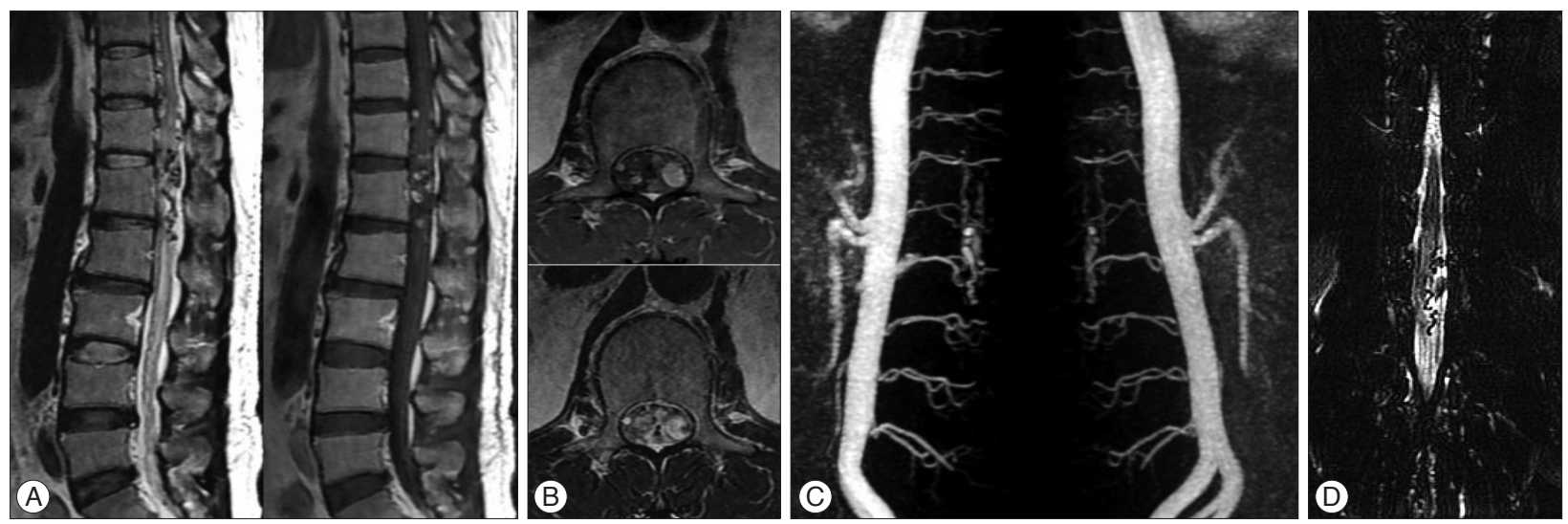

Fig. 1. Magnetic resonance imaging (MRI) of the thoracolumbar spine reveals abnormal lesions with signal void and enhancement, indicating a vascular anomaly at the T12, L1, and L2 levels (A). Axial images at the L1 level show a left-sided mass lesion in the spinal canal (B). Three-dimensional volumetric contrast-enhanced sagittal TRICKS abdominal magnetic resonance angiography (MRA) using 1.5T MRI system was performed. The study was post-processed into maximum-intensity projection images. These images show a feeding artery at the L1 level (C). Magnetic resonance myelography (anterior-posterior view) reveals a left-sided vascular anomaly (D).
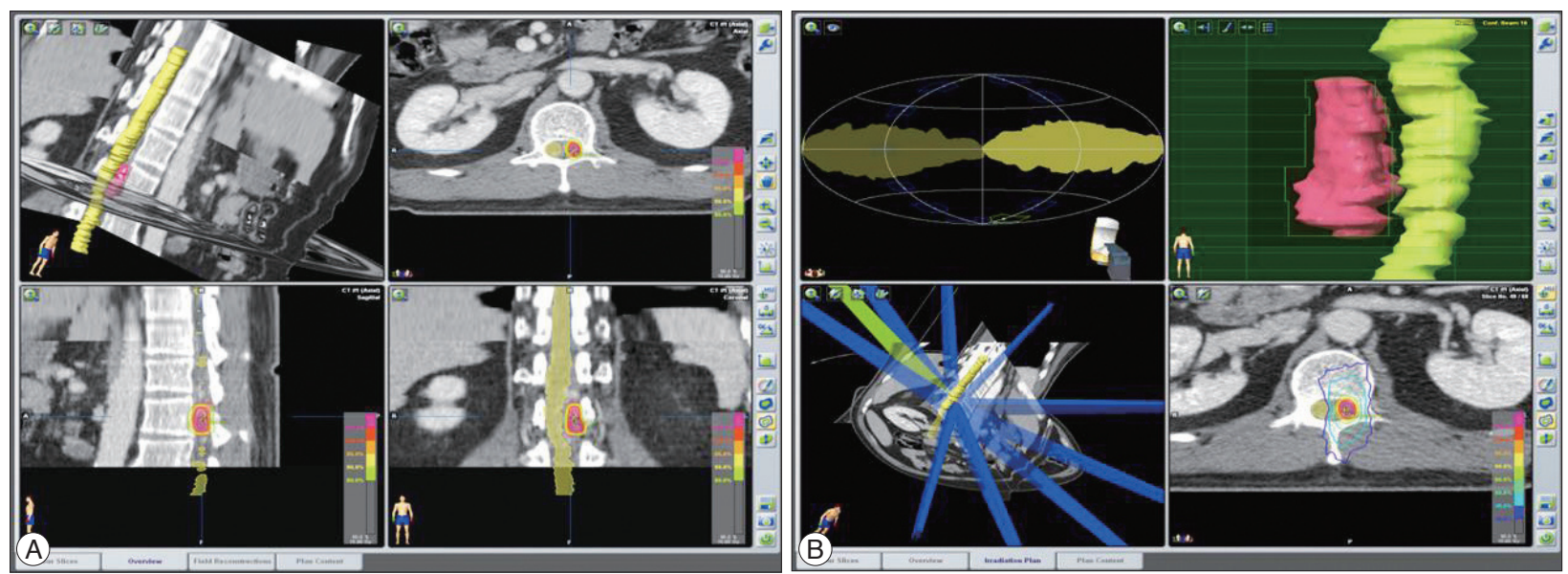

Fig. 2. View of the treatment plan. The target, involving the dura margin, was constructed to include the fistula during structural segmentation under spinal computed tomography imaging (A). Ten conformal beams were used, and a multileaf collimator shaped the target margin. The yellow isodose line represents the $90 \%$ isodose line and total prescribed dose of 18 Gy. The blue line represents the $30 \%$ isodose line (6 Gy). This treatment plan showed a low dose of radiation exposure to spinal cord (B).

$330 \times 330$, equivalent slice thickness of $3 \mathrm{~mm}$, matrix $256 \times 160$ ). Contrast medium (15 mL gadolinium) was administrated. The study was post-processed into maximum-intensity projection (MIP) images (Fig. 1C). These images showed the SDAVF feeding from the L1 lumbar artery. Magnetic resonance myelography showed a left-sided vascular anomaly (Fig. 1D). SRS through the Novalis system $\left(\right.$ BrainLAB $^{\circledR}$ ) was performed. The target, involving the dura margin, was constructed to include the fistula during structural segmentation under spinal computed tomography (CT) images (Fig. 2A). The volume of the lesion was 2.533 cc. We used 10 conformal beams and a total irradiation of $18 \mathrm{~Gy}$ with three fractions (Fig. 2B).

The patient's back pain improved 7 months after the treatment. Three years later, the patient could walk unassisted. But the voiding problem remained.

We checked the three-dimensional sagittal TRICKS abdominal MRA using 1.5T for follow-up 7 months after SRS, and three- dimensional sagittal TRICKS abdominal MRA using 3.0T MRI system $\left(\mathrm{TR} / \mathrm{TE} / \mathrm{flip}=10.0 / 1.5 / 30^{\circ}\right.$, FOV $380 \times 380$, equivalent slice thickness of $4 \mathrm{~mm}$, matrix $384 \times 160$ ) was performed 3 years after radiosurgery. The size of the spinal lesion was decreased and the flow through the fistula was diminished on the 7-month posttreatment images (Fig. 3). Three years after SRS, the feeding artery for the SDAVF disappeared (Fig. 4A), and the sequelae of the previous lesion was presented on follow-up MRI and MRA images (Fig. 4B).

\section{DISCUSSION}

SDAVF represent a rare pathological condition, but they account for $60-80 \%$ of all spinal vascular malformation ${ }^{6,13,17,18,20,23)}$. They are acquired lesions, and usually present with insidious and progressive symptoms, such as paraparesis and sensory deficits of the bladder, bowel, and lower extremities ${ }^{10,13,17,18)}$. As 
they present with non-specific and misleading clinical symptoms, the final diagnosis is sometimes delayed from the onset of neurological deficit ${ }^{5,6,12,13,17,19,23)}$. Their most common site is the thoracolumbar region, and the arteriovenous shunt is a low-flow shunt located at the dural sleeve of the spinal nerve root ${ }^{5,6,10,13,23)}$. The pathophysiology of SDAVF-induced spinal cord ischemia and myelopathy is due to increased venous pressure, venous congestion, and decreased spinal cord perfusion caused by shunting arterial blood into the venous side $e^{5,6,12,13,15,17,18,23)}$. Treatment methods for these lesions are microsurgery and endovascular embolization. Because the selection of treatment method is mediated by the physician's preference, the optimal treatment remains controversial ${ }^{5,23)}$.
Selective spinal angiography is regarded as an essential procedure to confirm and treat $\mathrm{SDAVF}^{5)}$. For successful surgery or endovascular coiling, selective spinal angiography is necessary to know the architectures and hemodynamics of the lesion ${ }^{5,6,12,15,18,19,22)}$. However, even with experienced neuro-interventionists, selective spinal angiography can sometimes cause complications from vasospasm, increased venous pressure, and spinal cord infarction $^{6,8,12,15,17,20)}$. In our case, the patient experienced paraparesis three times during spinal angiography. Although it occurred 14 years previously, the patient refused the spinal angiography. Because the patient wanted a noninvasive method for diagnosis and treatment, we found an imaging technique to provide information about the lesion and be available for follow-up. There
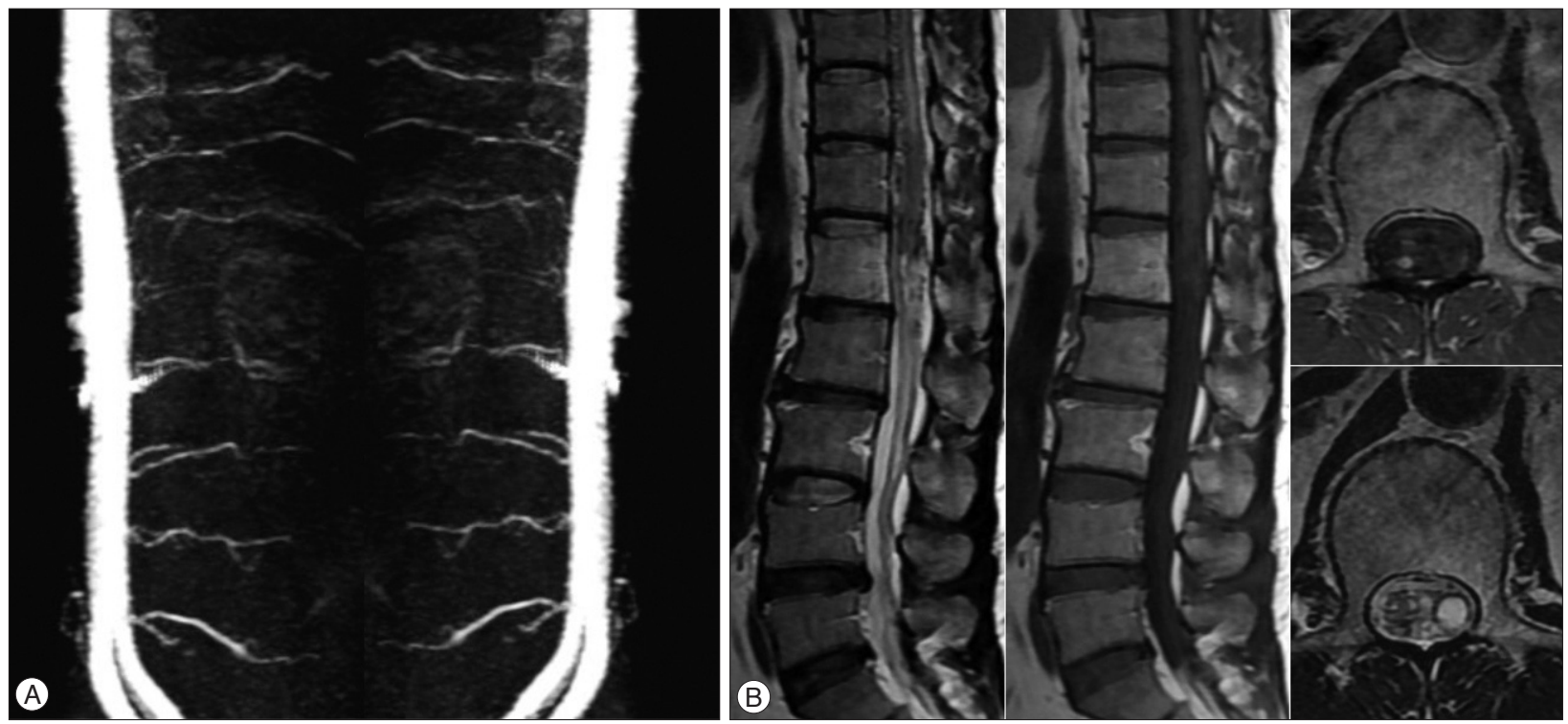

Fig. 3. Follow-up MRI and MRA images after 7 months. The size of the feeding artery and abnormal vascular lesion is decreased (A). The previous lesion with signal void and enhancement is also reduced (B).
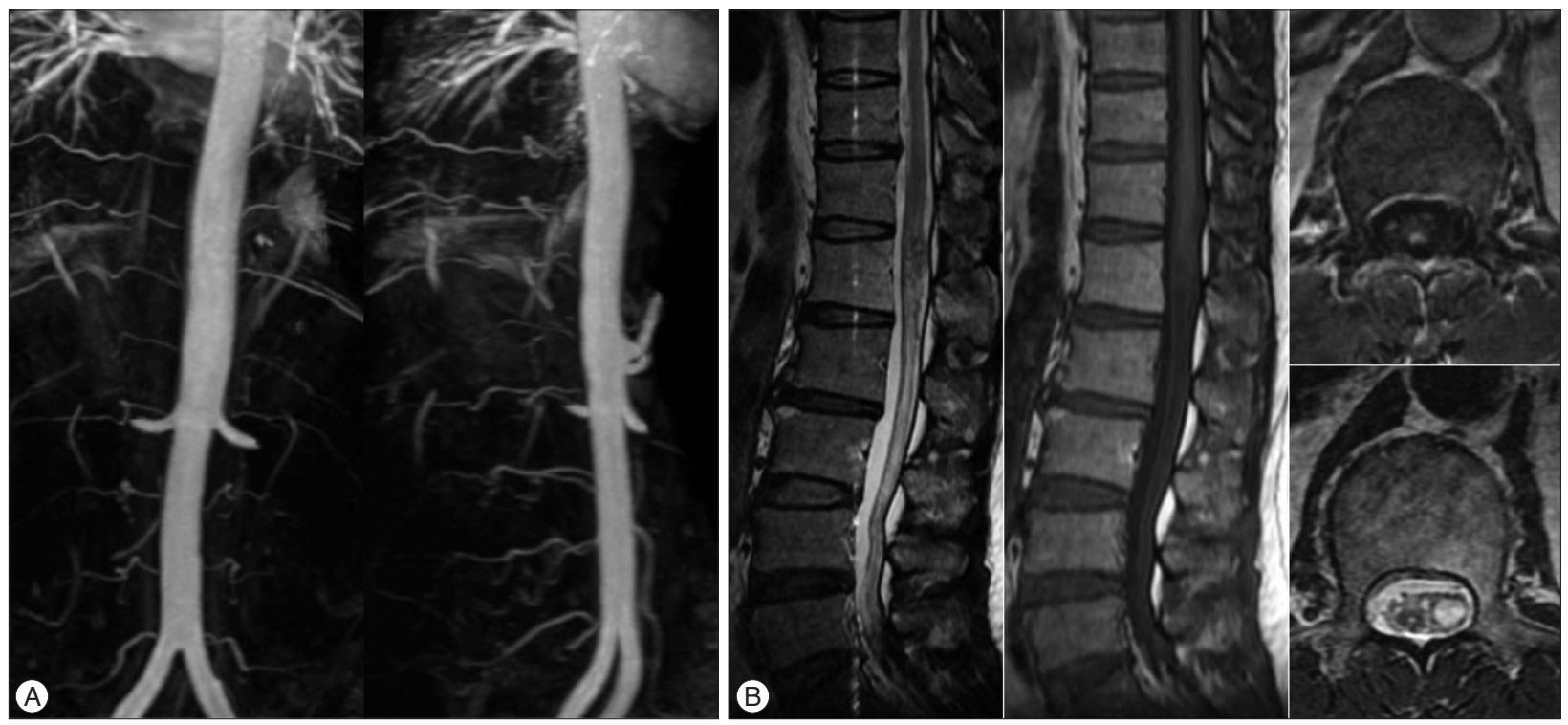

Fig. 4. Follow-up MRI and MRA images after 3 years show disappearance of the feeding artery of the spinal dural arteriovenous fistula $(\mathrm{A})$ and sequelae of the previous lesion (B). 
are some advanced imaging techniques for SDAVF, such as contrast enhanced magnetic resonance angiography with high resolution, TRICKS sequence, gradient echo, and spinal angiography with a 256-slice $\mathrm{CT}^{2,3,15,20,24)}$. Although the role of advanced imaging techniques is limited to reducing the exposure of contrast and radiation during the subsequent selective spinal angiography ${ }^{6,12,15,20,21,24)}$, it is sufficient for diagnosing SDAVF and localizing the fistula ${ }^{2,3,5,15,20,24)}$. Of these imaging techniques, we used the three-dimensional sagittal TRICKS abdominal MRA to obtain information about the spinal lesion and plan the SRS. We utilized TRICKS sequence for follow-up to confirm therapeutic effects.

SRS for SDAVF is not an established method, so reports regarding SDAVF treated by SRS are very rare. However, in terms of radiosurgery for cranial dural arteriovenous fistulas, radiosurgery for SDAVF is not an impossible treatment option ${ }^{22)}$. Gao et al. ${ }^{7)}$ reported that high expression state of endothelial progenitor cells (EPCs) presented in the brain and spinal arteriovenous malformation (AVM) tissue. Other authors have published the results from an experimental study that radiosurgery decreases angiogenic activity in AVM tissue, compared to that in untreated AVM tissue ${ }^{1)}$. Moreover, in an experimental study by Jahan et al. ${ }^{9)}$, SRS for an artificial animal AVM model showed a reduction in the size of the lesion, compared to that in the non-radiosurgical model. Although these studies are not results for SDAVF, we thought that it was possible to perform radiosurgery for SDAVF. Dalyai et al. ${ }^{4)}$ reported that SRS for arteriovenous fistula lesions did not clearly show the mechanisms of treatment results, but they induced smooth muscle expansion, adventitial fibrosis, and an intimal response of arterial feeders, and eventually achieved obliteration of the fistula.

There are some points of note regarding SRS for SDAVF. It is necessary to include the arterialized fistula in the SRS target. However, it is not easy to find the exact location of fistulas with CT and MRI-based image-guided structural segmentation. Thus, we planned the target area to include the dura margin, because fistulas of SDAVF are located at the sleeve of the nerve root in the intradural space ${ }^{5,13,18,22}$. The planning of the radiosurgical dose was based some study, which the appearance of myelopathy from SRS to spinal lesions appear rare $(<1 \%)$ when the maximum spinal cord dose is limited to the equivalent of $13 \mathrm{~Gy}$ in a single fraction or 20 Gy in three fractions ${ }^{11,14)}$. However, these studies did not provide sufficient long-term data, and our patient had preexisting myelopathy. Thus, we treated him with a slightly lower dose than those in the references.

\section{CONCLUSION}

Advanced imaging studies, including the three-dimensional sagittal TRICKS sequence, may be useful for obtaining information about SDAVF and in performing SRS and follow-up after SRS when selective spinal angiography has failed. And we think that SRS may be another treatment option, especially, for patients preferring non-invasive procedures. Our study has the obvious limitation of only including one treatment case, so additional cases of SDAVF treated by SRS are necessary to determine if it is an effective treatment for this condition.

\section{References}

1. Akakin A, Ozkan A, Akgun E, Koc DY, Konya D, Pamir MN, et al. : Endovascular treatment increases but gamma knife radiosurgery decreases angiogenic activity of arteriovenous malformations : an in vivo experimental study using a rat cornea model. Neurosurgery 66 : 121-129; discussion 129-130, 2010

2. Boeckh-Behrens T, Bitterling H, Schichor C, Brückmann H, Seelos K : [Improved localization of spinal AV fistulas using contrast-enhanced MR angiography at $3 \mathrm{~T}$ ]. Rofo 182 : 53-57, 2010

3. Cao JB, Cui LL, Jiang XY, Gao SJ, Sun WG, Xu K : Clinical application and diagnostic value of noninvasive spinal angiography in spinal vascular malformations. J Comput Assist Tomogr 38 : 474-479, 2014

4. Dalyai RT, Ghobrial G, Chalouhi N, Dumont AS, Tjoumakaris S, Gonzalez LF, et al. : Radiosurgery for dural arterio-venous fistulas : a review. Clin Neurol Neurosurg 115 : 512-516, 2013

5. Dehdashti AR, Da Costa LB, terBrugge KG, Willinsky RA, Tymianski $\mathrm{M}$, Wallace MC : Overview of the current role of endovascular and surgical treatment in spinal dural arteriovenous fistulas. Neurosurg Focus 26 : E8, 2009

6. Donghai W, Ning Y, Peng Z, Shuo X, Xueen L, Peng Z, et al. : The diagnosis of spinal dural arteriovenous fistulas. Spine (Phila Pa 1976) 38 : E546E553, 2013

7. Gao P, Chen Y, Lawton MT, Barbaro NM, Yang GY, Su H, et al. : Evidence of endothelial progenitor cells in the human brain and spinal cord arteriovenous malformations. Neurosurgery 67 : 1029-1035, 2010

8. Grunwald I, Thron A, Reith W : [Spinal angiography : vascular anatomy, technique and indications]. Radiologe 41 : 961-967, 2001

9. Jahan R, Solberg TD, Lee D, Medin P, Tateshima S, De Salles A, et al. : An arteriovenous malformation model for stereotactic radiosurgery research. Neurosurgery 61 : 152-159; discussion 159, 2007

10. Kikuchi Y, Miyasaka K: Treatment strategy of spinal arteriovenous malformations based on a simple classification. J Clin Neurosci 5 Suppl : 1619, 1998

11. Kirkpatrick JP, van der Kogel AJ, Schultheiss TE : Radiation dose-volume effects in the spinal cord. Int J Radiat Oncol Biol Phys 76 (3 Suppl) : S42S49, 2010

12. Luetmer PH, Lane JI, Gilbertson JR, Bernstein MA, Huston J 3rd, Atkinson JL : Preangiographic evaluation of spinal dural arteriovenous fistulas with elliptic centric contrast-enhanced MR angiography and effect on radiation dose and volume of iodinated contrast material. AJNR Am J Neuroradiol 26 : 711-718, 2005

13. Marcus J, Schwarz J, Singh IP, Sigounas D, Knopman J, Gobin YP, et al. : Spinal dural arteriovenous fistulas : a review. Curr Atheroscler Rep 15 : 335,2013

14. Milano MT, Usuki KY, Walter KA, Clark D, Schell MC : Stereotactic radiosurgery and hypofractionated stereotactic radiotherapy : normal tissue dose constraints of the central nervous system. Cancer Treat Rev 37 : 567-578, 2011

15. Mull M, Nijenhuis RJ, Backes WH, Krings T, Wilmink JT, Thron A : Value and limitations of contrast-enhanced MR angiography in spinal arteriovenous malformations and dural arteriovenous fistulas. AJNR Am J Neuroradiol 28 : 1249-1258, 2007

16. Oumerzouk J, Jouehari A, Hssaini Y, Raggabi A, Bourazza A : Sudden worsening of paraparesis complicating dorsal dural arteriovenous fistula after spinal angiography : case report and review of literature. Rev Neurol (Paris) $169:$ 356-358, 2013 
17. Park KW, Park SI, Im SB, Kim BT : Spinal dural arteriovenous fistula with supply from the lateral sacral artery-case report and review of literature-. J Korean Neurosurg Soc 45 : 115-117, 2009

18. Rashad S, Abdel-Bary M, Aziz W, Hassan T: Management of spinal dural arterio-venous fistulas. Report of 12 cases and review of literature. Clin Neurol Neurosurg $125: 81-86,2014$

19. Reith W, Kettner M, Simgen A, Yilmaz U : [Spinal dural arteriovenous fistulas : diagnostics and therapy]. Radiologe 52 : 437-441, 2012

20. Saindane AM, Boddu SR, Tong FC, Dehkharghani S, Dion JE : Contrastenhanced time-resolved MRA for pre-angiographic evaluation of suspected spinal dural arterial venous fistulas. J Neurointerv Surg 7 : 135140,2015

21. Saraf-Lavi E, Bowen BC, Quencer RM, Sklar EM, Holz A, Falcone S, et al. : Detection of spinal dural arteriovenous fistulae with MR imaging and contrast-enhanced MR angiography : sensitivity, specificity, and prediction of vertebral level. AJNR Am J Neuroradiol 23 : 858-867, 2002

22. Steiger HJ, Hänggi D, Schmid-Elsaesser R : Cranial and spinal dural arteriovenous malformations and fistulas : an update. Acta Neurochir Suppl $94: 115-122,2005$

23. Steinmetz MP, Chow MM, Krishnaney AA, Andrews-Hinders D, Benzel EC, Masaryk TJ, et al. : Outcome after the treatment of spinal dural arteriovenous fistulae : a contemporary single-institution series and metaanalysis. Neurosurgery $55:$ 77-87; discussion 87-88, 2004

24. Toni F, Cirillo L, Marliani AF, Albini Riccioli L, Leonardi M : Role of contrast-enhanced magnetic resonance angiography in spinal dural arteriovenous fistula. Neuroradiol J 23 : 234-243, 2010 